\title{
The Effect of Fixed Charge Modifications on Electron Capture Dissociation
}

\author{
Xiaojuan $\mathrm{Li}_{,}{ }^{\mathrm{a}}$ Jason J. Cournoyer, ${ }^{\mathrm{b}}$ Cheng Lin, ${ }^{\mathrm{a}}$ and Peter B. O'Connor ${ }^{\mathrm{a}}$ \\ a Mass Spectrometry Resource, Department of Biochemistry, Boston University School of Medicine, Boston, \\ Massachusetts, USA \\ ${ }^{b}$ Department of Chemistry, Boston University, Boston, Massachusetts, USA
}

\begin{abstract}
Electron capture dissociation (ECD) studies of two modified amyloid $\beta$ peptides (20-29 and 25-35) were performed to investigate the role of $\mathrm{H}^{*}$ radicals in the ECD of peptide ions and the free-radical cascade (FRC) mechanism. 2,4,6-Trimethylpyridinium (TMP) was used as the fixed charge tag, which is postulated to both trap the originally formed radical upon electron capture and inhibit the $\mathrm{H}^{*}$ generation. It was found that both the number and locations of the fixed charge groups influenced the backbone and side-chain cleavages of these peptides in ECD. In general, the frequency and extent of backbone cleavages decreased and those of side-chain cleavages increased with the addition of fixed charge tags. A singly labeled peptide with the tag group farther away from the protonated site experienced a smaller abundance decrease in backbone cleavage fragments than the one with the tag group closer to the protonated site. Despite the nonprotonated nature of all charge carriers in doubly labeled peptide ions, several $\mathrm{c}$ and $\mathrm{z}^{\bullet}$ ions were still observed in their ECD spectra. Thus, although $\mathrm{H}^{\bullet}$ transfer may be important for the $\mathrm{N}-\mathrm{C}_{\alpha}$ bond cleavage, there also exist other pathways, which would require a radical migration via $\mathrm{H}^{\bullet}$ abstraction through space or via an amide superbase mechanism. Finally, internal fragment ions were observed in the ECD of these linear peptides, indicating that the important role of the FRC in backbone cleavages is not limited to the ECD of cyclic peptides. (J Am Soc Mass Spectrom 2008, 19, 1514-1526) (C 2008 American Society for Mass Spectrometry
\end{abstract}

$\mathrm{I}$ contrast with slow heating fragmentation methods such as infrared multiphoton dissociation (IRMPD) [1] and collisionally activated dissociation (CAD) [2], electron capture dissociation (ECD) [3] of multiply charged peptide/protein ions is often considered as a "directed" tandem mass spectrometric (MS/MS) method since it nonspecifically cleaves many backbone bonds while frequently leaving the more labile groups [4-8] and noncovalent interactions [9-13] intact. Because of these unique properties, it has significant applications in both top-down and bottom-up sequencings for protein identification $[3,7,14-16]$, as well as in post-translational modification (PTM) characterization $[4,17,18]$. The ECD process is the dissociative recombination of multiply charged peptide/protein ions with low-energy electrons $[3,17,19]$. The major products of the electron capture are often the charge-reduced species, $[\mathrm{M}+n \mathrm{H}]^{(n-1)+\bullet}$, and the $\mathrm{H}^{\bullet}$ loss product, $[\mathrm{M}+$ $(n-1) \mathrm{H}]^{(n-1)+}[20]$. There are two backbone fragmentation pathways: the major one produces $\mathrm{c}$ and $\mathrm{z}^{\circ}$ (or $\mathrm{c}^{\circ}$ and $\mathrm{z}$ ) ions via $\mathrm{N}-\mathrm{C}_{\alpha}$ bond cleavage and the minor pathway generates $\mathrm{a}^{\bullet}$ and $\mathrm{y}$ ions $[3,17,19]$. In addition, ECD may also produce some amino acid side-chain cleavages [21-23] and secondary fragment ions [24-26].

Address reprint requests to Professor Peter B. O'Connor, Mass Spectrometry Resource, Department of Biochemistry, Boston University School of Medicine, 670 Albany St., Room 504, Boston, MA 02118. E-mail: poconnor@bu.edu
Currently, two primary mechanisms have been proposed to explain the abundant $c^{-}$and $\mathrm{z}^{\circ}$-type ions observed in the ECD spectra of peptides. In the dissociation-recapture mechanism, the initially captured electron in a high-lying Rydberg state may land in one of the protonated sites and the resultant $\mathrm{H}^{*}$ from the dissociation of the neutralized ammonium group (or other charged groups) can be recaptured by a nearby carbonyl oxygen atom, yielding an aminoketyl intermediate that dissociates via the $\mathrm{N}-\mathrm{C}_{\alpha}$ bond cleavage [17]. Since the cross section for gas-phase peptide ions to capture a free hydrogen atom is low $[19,27]$, it was argued to be unlikely that the abundant backbone cleavages were induced by the mobile hot hydrogen from the neutralization of a charged amino or guanidine group. Such cleavages were probably initiated by a concerted dissociation-recapture process upon electron capture arising from the extensive solvations of the charged sites by multiple backbone carbonyls, which may also be followed by secondary fragmentations [26]. The low selectivity in backbone cleavages and preservation of labile groups during ECD were attributed to the nonergodic nature of this process, i.e., the $\mathrm{N}-\mathrm{C}_{\alpha}$ bond cleavage occurs before the approximately $6-\mathrm{eV}$ recombination energy was randomized among the $3 \mathrm{~N}-6$ normal vibrational modes in the peptide molecule via intramolecular vibrational energy redistribution (IVR), which would result in millielectronvolts of energy per 
mode, clearly far below the normal adiabatic bond dissociation energies [3, 17]. The nonergodic premise has been scrutinized heavily as of late $[19,28]$, and the necessity of the presence of a hydrogen atom to initiate $\mathrm{N}-\mathrm{C}_{\alpha}$ bond cleavages was also under debate $[8,29]$. In the recently proposed amide-superbase mechanism, it was argued that the electron is first captured in the remote-charge (Coulomb) stabilized $\pi^{*}$ orbital of a backbone carbonyl, generating an aminoketyl anion (a super base), which abstracts a nearby proton, and the resultant aminoketyl radical undergoes facile cleavage of the adjacent $\mathrm{N}-\mathrm{C}_{\alpha}$ bond with a very low (or nonexistent) energy barrier, thus eliminating the need to evoke the nonergodic hypothesis, as well as the necessary presence of a hydrogen atom $[19,30]$. Furthermore, many $\mathrm{H}^{\bullet}$ abstraction reactions in peptides, in addition to having low activation barriers, are also net exothermic reactions, as the radical moves to a more stable site. It was further suggested that both mechanisms might be at work depending on the electronic states of the peptide ions $[19,31]$.

Either of these two mechanisms addresses only the formation of the $\mathrm{c}$ - and $\mathrm{z}^{\bullet}$-type ions, but does not explain the many other types of fragment ions also present in the ECD spectra. In particular, in the ECD spectra of doubly charged cyclic peptide ions, many backbone fragment ions were observed, which requires multiple backbone cleavages by a single electron capture. It was proposed that these ions resulted from the free-radical cascade (FRC), i.e., the radical site on the initially produced $z^{\bullet}$ ion could initiate secondary fragmentations via hydrogen abstraction and/or loss of neutrals such as diketopiperazines [26]. For linear peptides, hydrogen atom migrations within the post-ECD complex are also frequently observed. In an ECD study of peptides with all glycine alpha hydrogens replaced by deuterons, many fragment ions showed extensive $\mathrm{H} / \mathrm{D}$ scramblings [32]. Moreover, $\mathrm{c}^{\bullet}-$ and $\mathrm{z}$-ion formations are common in peptide ion ECD spectra [33], which has been demonstrated to be the result of the intracomplex hydrogen transfer between the originally formed $c / z^{\bullet}$ ion pair $[13,33,34]$. A double-resonance (DR)-ECD experiment showed that a long-lived freeradical intermediate existed in the ECD process [11], and that its lifetime was often much longer than the time it took for the intracomplex hydrogen transfer [13]. However, evidence for multiple backbone cleavages resulting in the formation of internal ions in the ECD of linear peptide ions was lacking to date, most likely as a result of the location of charges near the termini for the tryptic peptides studied. Experimental evidence linking the formation of smaller $\mathrm{z}^{\bullet}$ ions to the FRC of larger ones was also lacking because the resonant ejection of the latter during ECD did not lead to an appreciable decrease in smaller $z^{\bullet}$-ion abundances [11]; thus, if the FRC is to account for some of the smaller $z^{\bullet}$-ion formation, it must have taken place on a timescale shorter than the ejection time (typically milliseconds). Nevertheless, the FRC may still play an important role in the ECD of linear peptides, as evidenced by the abundant secondary side-chain cleavages and radical rearrangement, particularly when there is extra energy deposited in the precursor ions [13, 24, 25, 35, 36].

The importance of the radical in ECD was investigated further by several research groups with added radical trap moieties in the peptide [37, 38]. In one study, coumarin labels were attached to the N-terminal and/or lysine side-chain amine groups to serve as radical traps, which appeared to inhibit the $\mathrm{c} / \mathrm{z}$-ion formation while enhancing the side-chain cleavages in ECD [37]. In another study, a 2-(4'-carboxypyrid-2'-yl)4-carboxamide group (pepy) moiety was used as the stable trap for both the electron and the hydrogen, which resulted in abundant electron capture without backbone dissociation. When the precursor ions were preheated by an IR laser near the dissociation threshold, subsequent electron capture did trigger backbone dissociation, but produced only b-type ions [38]. These studies demonstrated the instrumental role of the mobility of the radical in peptide ion ECD.

In this study, a different radical trap, 2,4,6trimethylpyridinium (TMP), was used. In addition to its potential of being a stable radical trap, TMP also functions as a fixed charge that inhibits the $\mathrm{H}$ atom formation upon electron capture and does not form hydrogen bonds with backbone carbonyls in the precursor ions. This may shed light on our understanding of both the primary and secondary ECD mechanisms. Charge derivatization methods using both positively and negatively charged derivatives have been used in mass spectrometry research to control the type of fragment ions generated from peptides and to facilitate the interpretation of the mass spectral data [39-44]. In several recent ECD and the related electron-transfer dissociation (ETD) [45] studies, fixed charge derivatization was used to increase the sequence coverage, investigate the role of excited electronic states, study the effects of cation charge-site identity, and examine the mechanism of disulfide bond cleavages [31, 46-48].

\section{Experimental}

\section{Materials}

Amyloid $\beta$ peptides (20-29, FAEDVGSNKG, hereafter abbreviated as A $\beta$ 20) and (25-35, GSNKGAIIGLM, hereafter abbreviated as $A \beta$ 25) were purchased from Bachem AG (Philadelphia, PA, USA) and used without further purification. 2,4,6-Trimethylpyrylium tetrafluoroborate was purchased from Alfa Aesar (Ward Hill, MA, USA). Poros 50 R1 material was purchased from Applied Biosystems (Foster City, CA, USA). All other chemicals were purchased from Sigma (St. Louis, MO, USA). 


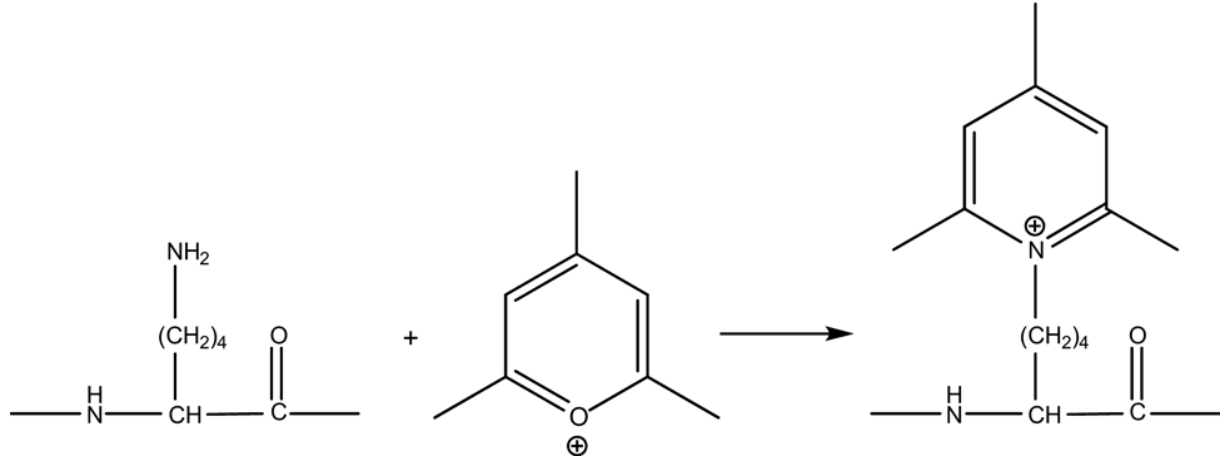

Scheme 1. The $\varepsilon$-amino group of the lysine side chain was selectively converted to a $2,4,6$ trimethylpyridinium salt.

\section{Peptide Derivatization}

Potassium carbonate buffer solution (0.1 $\mathrm{M} \mathrm{K}_{2} \mathrm{CO}_{3}$ and $0.1 \mathrm{M} \mathrm{NaHCO}$ ) containing about $0.05 \mathrm{M} \mathrm{2,4,6-}$ trimethylpyrylium tetrafluoroborate was prepared, the $\mathrm{pH}$ of which was adjusted to about 9 using approximately $10 \mu \mathrm{L}$ of $\mathrm{HCl}$. A $20 \mathrm{nmol}$ aliquot of each peptide was dissolved in $50 \mu \mathrm{l}$ of this buffer solution, respectively vortexed and purged with nitrogen gas. The reaction was allowed to proceed for $18-24 \mathrm{~h}$ at room temperature. The final reaction solutions were dried and the peptide derivatives were purified by Poros 50 R1 material in custom solid-phase microextraction (SPME) tips. Each fraction of the eluate was analyzed, and unlabeled, singly labeled, and doubly labeled fractions were identified by electrospray ionization (ESI) Fourier-transform ion cyclotron resonance mass spectrometry (FT-ICR-MS or FTMS).

\section{ECD Experiments}

Unlabeled, singly labeled, and doubly labeled model peptides were analyzed by ECD at about $10^{-5} \mathrm{M}$ concentration in 49.5:49.5:1 methanol:water:formic acid spray solution. The ECD analysis was performed in a custom qQq-FT-ICR-MS equipped with an external nanospray source and a 7 Telsa actively shielded superconducting magnet as described previously [49, 50]. Multiply charged precursor ions were isolated by the front-end quadrupole (Q1) followed by external accumulation in the collision cell (Q2) for about 100-600 ms, before they were transferred via two rf-only hexapoles and trapped in the ICR cell using the gated trapping. These trapped ions were then irradiated with lowenergy electrons $(\sim 0.2 \mathrm{eV})$ for $50-120 \mathrm{~ms}$, generated by the indirectly heated dispenser cathode (Heatwave, Watsonville, CA, USA). A chirp excitation/detection sequence was used and the signal was averaged for 20 scans. All spectra were zero filled once without apodization and Fourier transformed to give the magnitude mode spectra. Internal calibration using the molecular ion and the charge reduced species gave a typical mass accuracy of $<2$ ppm for most of the peaks identified.

\section{Results and Discussion}

The derivatization reaction of peptides with TMP was previously used to convert the $\varepsilon$-amino group of the lysine side chain to the charged TMP group (Scheme 1) [51-53]. Even though each of the $\mathrm{A} \beta$ peptides studied here has only one lysine residue, some doubly tagged peptides were also produced, where the second tag must have gone to the $\mathrm{N}$-terminal amino group. The singly tagged peptides may exist in one of the two forms, with either the lysine side chain or the Nterminal amino group modified. Since the TMP tagging causes a mass shift of approximately $104 \mathrm{Da}$ (from the charged amino group as it introduces a fixed charge) per modification, it was possible to localize the TMP group in the lysine residue rather than at the N-terminus (see following text). The TMP group also fixed the charge at the nitrogen atom on the pyridinium ring, eliminating the existence of (relatively) free protons in the doubly tagged peptides, which allows study of the role of hydrogen atom in the ECD process. Furthermore, the aromatic structure of the pyridinium ring could trap the radical generated near the TMP group, making it unlikely to propagate and induce further reactions.

Before analyzing the results obtained in the ECD studies of these modified peptides and attempting to draw conclusions on the ECD mechanism, it is important to point out that the modification also significantly changes the peptide conformational and electronic structures, which may influence the outcome of the electron capture, such as the preferential neutralization site and the ECD product branching ratios for different fragmentation channels.

\section{Backbone Cleavages}

The ECD spectra of the unlabeled and both singly and doubly labeled amyloid $\beta$ peptides are shown in Figure 1 $(\mathrm{A} \beta 20)$ and Figure $2(\mathrm{~A} \beta 25)$, with the insets showing the cleavage patterns for the corresponding peptides. ECD of the unmodified $A \beta 20$ gave rise to many $c-$ and z-type ions (Figure 1a), reflecting the charge locations 


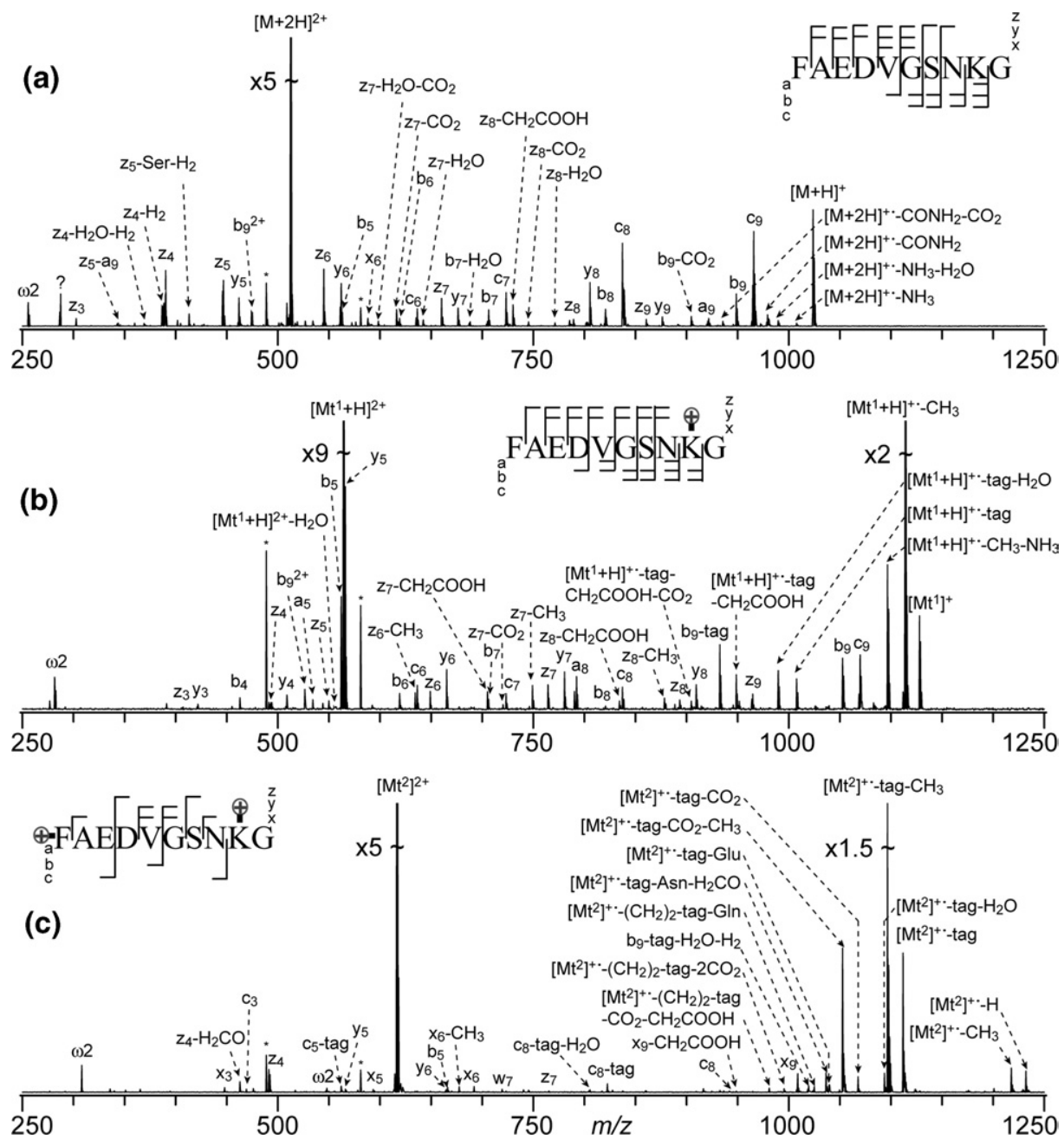

Figure 1. ECD spectra of the (a) unlabeled, (b) singly labeled, and (c) doubly labeled amyloid $\beta$ peptide (20-29). * marks the electronic noise peak, $\omega 2$ marks the first harmonic peak of the precursor ion, peaks marked with "-amino acid residue" resulting from cleavage at the $\mathrm{C}_{\alpha}-\mathrm{C}_{\beta}$ bond, and partial side-chain losses were represented by the molecular formulas of the departing group(s). Tagged precursor ions were labeled as $\left[\mathrm{Mt}^{1}+\mathrm{H}\right]^{2+}$ and $\left[\mathrm{Mt}^{2}\right]^{2+}$ for the singly and doubly labeled peptides, respectively. Cleavage patterns are shown as the insets.

near both the $\mathrm{N}$ - and $\mathrm{C}$-termini, as well as the similar recombination energy of the charged $\mathrm{N}$-terminal amino group and the lysine side chain. On the other hand, ECD of the unmodified $\mathrm{A} \beta 25$, with both charges located near the $\mathrm{N}$-terminus, produced mostly $\mathrm{N}$-terminal (b-and c-type) ions, with the only $\mathrm{z}$ ion $\left(\mathrm{z}_{8}\right)$ being the one that contains the lysine residue (Figure $2 \mathrm{a}$ ). Some a and y ions were also present, likely the products of the minor channel in ECD that produces a- and y-type ions [54]. In addition, abundant $b$ ions were observed in both spectra, a phenomenon that was previously investigated by Copper et al., who found that the b-ion formations were common in ECD of peptides, particularly those containing lysines but not arginines [25, 55]. Such would be the case if the electron capture deposited sufficient energy into the precursor ion that resulted in the formation of the excited $[\mathrm{M}+(n-1) \mathrm{H}]^{(n-1)+}$ ion (the hydrogen atom loss product), which was an even- electron species that could follow the mobile proton dissociation pathway to produce b-type ions.

ECD spectra of the singly labeled $A \beta 20$ and $A \beta 25$ are shown in Figures $1 b$ and $2 b$, respectively. For $A \beta 20$ peptide, all $\mathrm{z}$ ions and the $c_{9}$ ion displayed a roughly 104-Da mass shift from those produced in the ECD of its unmodified counterpart, but smaller $\mathrm{c}$ ions that do not contain the lysine residue showed no such mass shift; thus, the TMP tag was added to the lysine residue rather than at the $\mathrm{N}$-terminus. Likewise, for $\mathrm{A} \beta 25$ peptide, all fragment ions containing the lysine residue displayed the characteristic nominal 104-Da mass shift, whereas those without the lysine residue showed none, unambiguously locating the TMP tag at the side chain of the lysine residue.

The addition of a single TMP tag appeared to greatly reduce the abundance of the backbone fragments, but not the number of cleavages. The intrinsic recombina- 


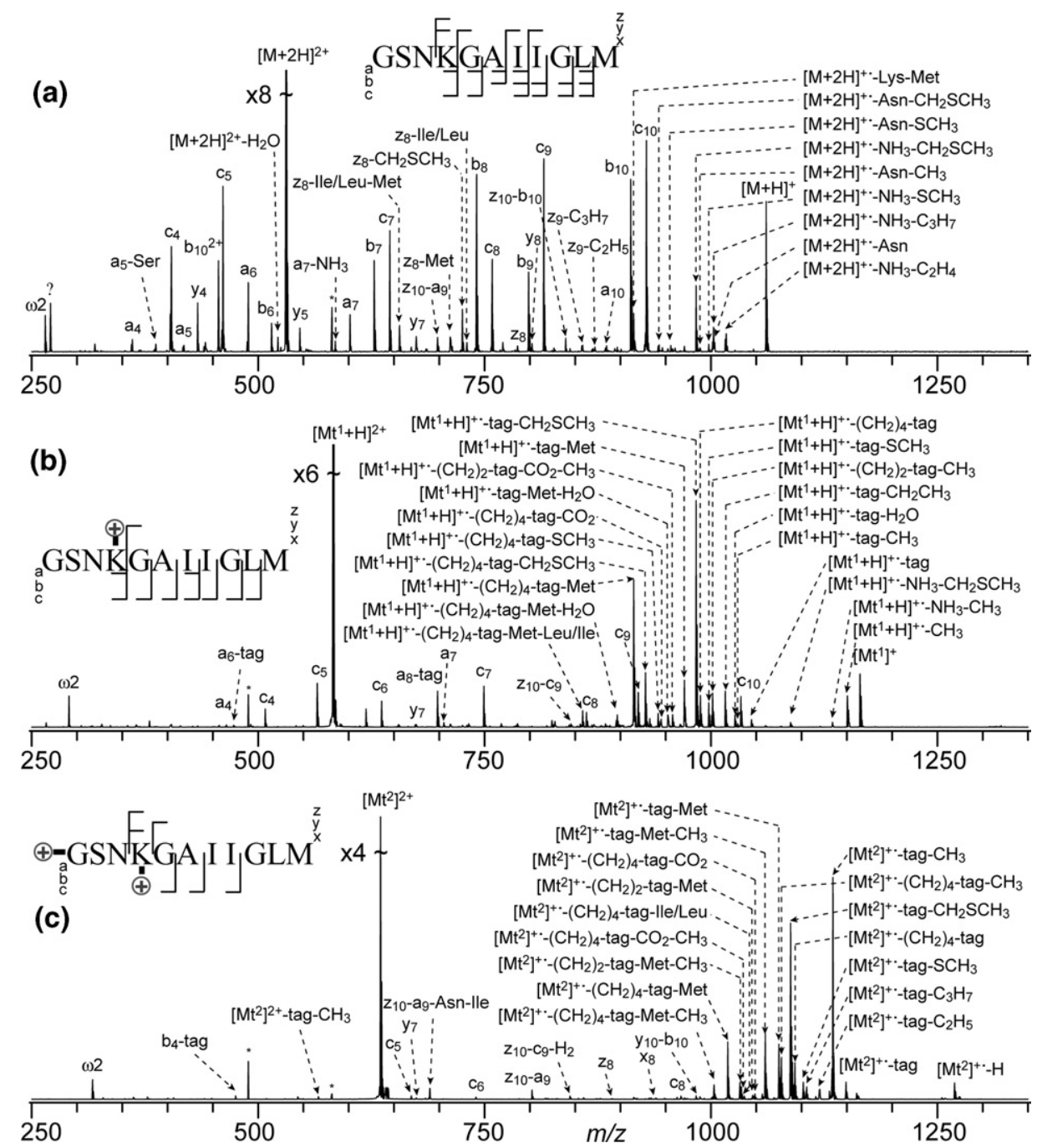

Figure 2. ECD spectra of the (a) unlabeled, (b) singly labeled, and (c) doubly labeled amyloid $\beta$ peptide (25-35). Peak labeling follows the same convention as in Figure 1. Cleavage patterns are shown as the insets.

tion energy of the pyridinium ion $(4.71 \mathrm{eV})[56]$ is much greater than that of the N-terminus protonated peptide $(3.71 \mathrm{eV})$ [57]. After the initial electron capture in a high-lying Rydberg state, the pyridinium is far more likely to be the eventual neutralization site than the protonated $\mathrm{N}$-terminal amino group. This resulted in the formation of a stable radical that was unlikely to undergo the typical c/z dissociations. However, it appeared that there was still a small but significant probability that the electron ended up at the N-terminus, leading to the observed $\mathrm{N}-\mathrm{C}_{\alpha}$ cleavages (see following text).

Both the abundance and frequency of the backbone $\mathrm{N}-\mathrm{C}_{\alpha}$ cleavages were greatly reduced with the addition of a second TMP tag at the N-terminus (Figures 1c and $2 \mathrm{c}$ ), as one would expect from the dissociationrecapture mechanism, since both charges were "fixed," and no $\mathrm{H}$ atom formation was initially expected upon electron capture. However, $\mathrm{N}-\mathrm{C}_{\alpha}$ cleavages were not completely eliminated from the ECD of these doubly tagged peptides, and there were also some $\mathrm{H}$ loss products present, albeit in much lower abundance. These $\mathrm{H}$ atoms were probably lost from the methyl groups on the pyridinium ring after it was neutralized, as shown in Scheme 2, leading to the formation of stable even-electron species, which could not undergo further radical driven reactions. Since the recapture cross section of a free $\mathrm{H}$ atom by a gas-phase peptide ion was very low, and the solvation of the TMP group by backbone carbonyls leading to the concerted $\mathrm{H}$ atom transfer from the methyl group to the carbonyl oxygen appeared unlikely, there must exist a second pathway to account for the observed $\mathrm{c} / \mathrm{z}$ ions in the ECD spectra of these doubly labeled peptides.

One possibility is that the electron was first neutralized near the TMP moiety, and the resulting radical at the alpha carbon on the pyridine ring could abstract a hydrogen atom from a nearby (through space) amino acid residue side-chain beta carbon, generating a beta radical that could lead to $\mathrm{c} / \mathrm{z}$ and $\mathrm{a} / \mathrm{x}$ ion formations 


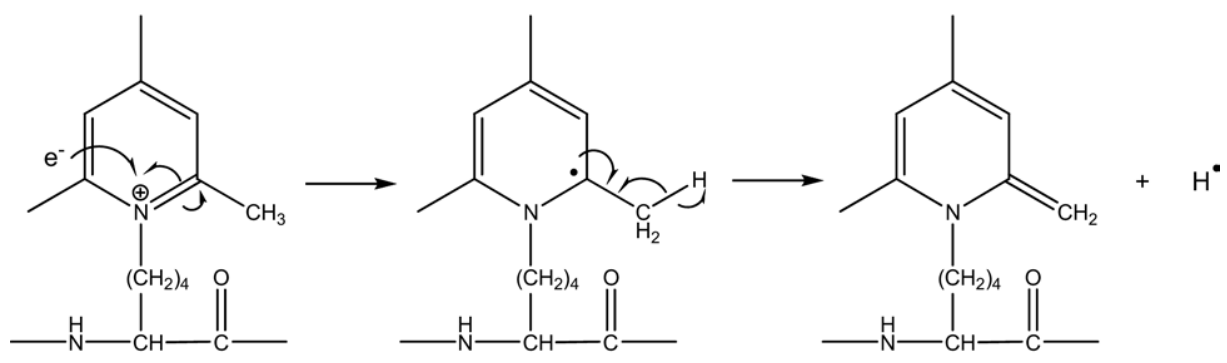

Scheme 2. H loss from the TMP tag upon electron capture.

(Scheme 3). Free-radical-driven backbone cleavages have been reported by Beauchamp and colleagues in their free-radical-initiated peptide sequencing (FRIPS) studies [58] and were recently applied in the radicaldirected dissociation of whole proteins in the gas phase [59]. In this study, however, the initially produced alpha radical on the pyridine ring was supposed to be fairly stable and unlikely to propagate; more importantly, the FRIPS mechanism (Scheme 3 ) calls for the formation of $\mathrm{c}^{\bullet}$ ions and $\mathrm{z}^{\bullet}-\mathrm{H}$ ions, whereas in the ECD spectra, only the even-electron $\mathrm{c}$ ions and odd-electron $\mathrm{z}^{\bullet}$ ions were observed. Thus, the FRIPS-like mechanism cannot account for all the backbone fragment ions observed here. A second possibility is that an amide superbase mechanism could be at work, where coulomb-assisted dissociative electron attachment at the backbone carbonyls generated an aminoketyl anion radical that abstracted a nearby proton to produce an aminoketyl radical that could undergo facile $\mathrm{N}-\mathrm{C}_{\alpha}$ bond cleavages.
The proton most likely came from the methyl group on the pyridinium ring because its acidity was increased by the positive charge on the nitrogen atom. Further experiments using a deuterium-labeled TMP tag would be helpful in determining the origin of the protons.

Although the number of the fixed charge tags appeared to have a profound effect on the abundance and frequency of the backbone cleavages, the position of these tags seemed to have a less dramatic influence. For the doubly tagged $A \beta 20$, either of the two TMP tags could be the neutralization site or the site that provided the proton during ECD, as substantiated by the observation of the $c_{3}, c_{8}$ ions, which must have retained the charge at the N-terminal TMP tag, and the $z_{4}, z_{7}$ ions, which must have had the lysine side-chain TMP tag as the charge carrier (Figure 1c). For the doubly tagged $A \beta$ 25 , the N-terminal TMP tag was a possible neutralization site, as indicated by the presence of $\mathrm{z}_{8}$ and $\mathrm{x}_{8}$ ions (Figure 2c), but it was unclear whether the tag on the
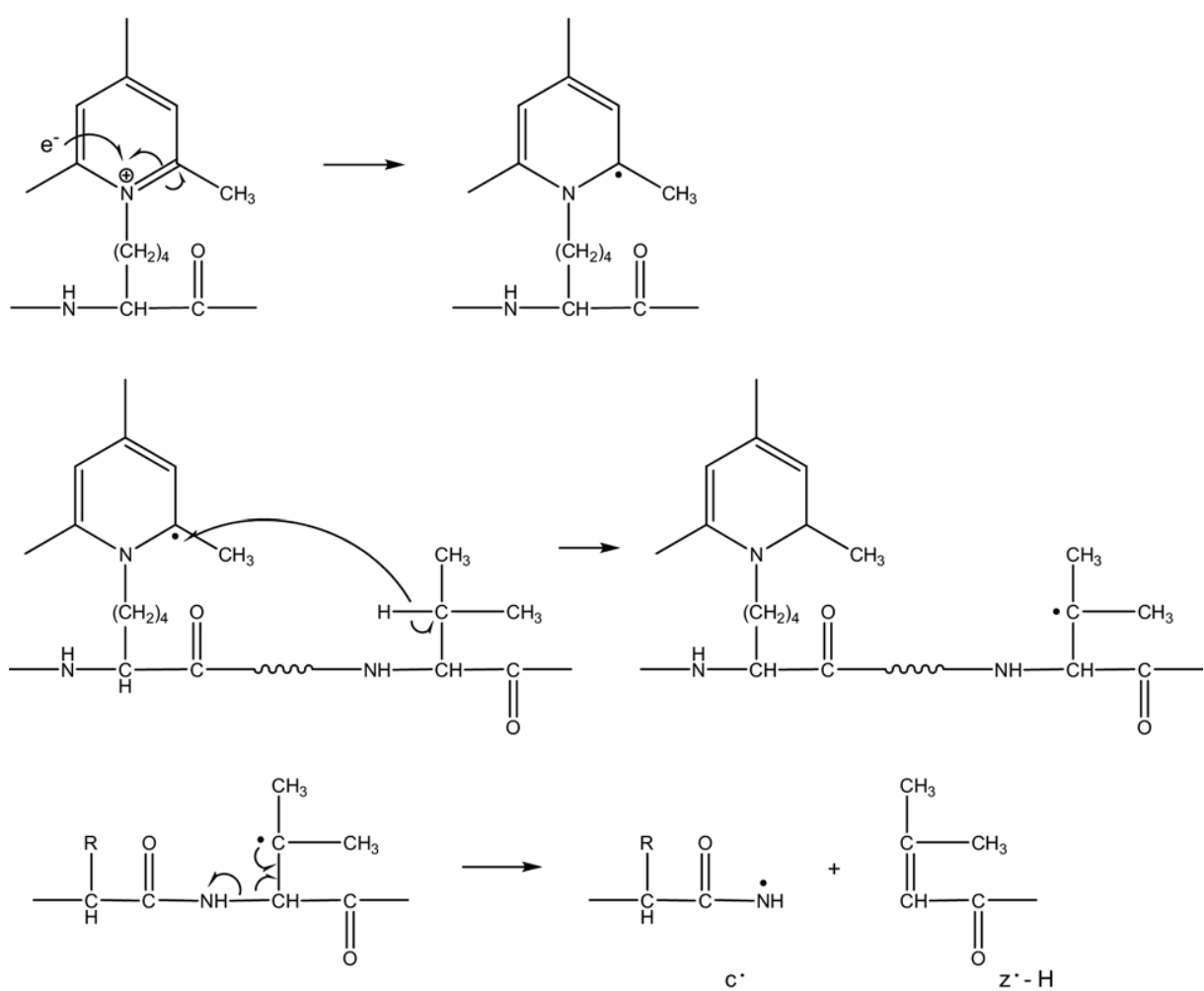

Scheme 3. One possible mechanism for $\mathrm{c} / \mathrm{z}$ ion formations in doubly tagged peptides. 
lysine side chain could also contribute to provide the proton necessary for backbone cleavages, given that all observed fragments contained the lysine residue. Moreover, the cleavages did not appear to be limited to regions that were adjacent to the charged sites in the sequence. This would certainly be true for remote charge-assisted electron capture at backbone carbonyls, and it would also be expected if these cleavages were the results of the through-space radical propagation. Previously, cleavages occurring spatially but not necessarily sequentially close to the initially formed radical site have been observed [60].

The singly tagged peptides did show some differences in backbone cleavage abundances. When the tag was far away from the protonated site as in the case of the $\mathrm{A} \beta 20$ peptide, only moderate drops in z-ion abundances were observed (Figure $1 \mathrm{a}$ and $\mathrm{b}$ ). The $\mathrm{c}$ ions showed slightly more abundance decrease because their formations required the TMP tag site to be neutralized, which did not easily lead to $\mathrm{N}-\mathrm{C}_{\alpha}$ bond cleavages. For the $\mathrm{A} \beta 25$ peptide (Figure $2 \mathrm{a}$ and $\mathrm{b}$ ), almost all fragment ions showed a significant decrease in abundance in the ECD spectrum of the singly labeled peptide. This might be a result of the close proximity of the protonated site and the TMP-tagged site in the A $\beta 25$ peptide, which would greatly reduce the probability that the electron capture occurred on the protonated N-terminal site. In addition, tag locations also seemed to influence the abundances of various side-chain loss and tag loss products (see following text).

Aside from backbone cleavages, fragment ions that resulted from small molecule losses, single or multiple side-chain cleavages, or a combination of backbone, side-chain cleavages and small molecule losses were also observed in the ECD spectra of all $\mathrm{A} \beta$ peptides studied here. These fragment ions were labeled in Figures 1 and 2, with their observed and theoretical masses listed in the Supplementary Tables S1-S6, which can be found in the electronic version of this article. All observed cleavages were also summarized in Figures 3 and 4 .

\section{Tag and Alkyl Group Losses}

It was previously shown in a neutralization-reionization study of gas-phase pyridinium ion that the pyridinium radical preferentially lost the $\mathrm{N}$-bound $\mathrm{H}$ or $\mathrm{D}$ atom to re-form the aromatic ring [56], which competed favorably over the hydrogen rearrangement within the pyridinium ring. For the doubly TMP-tagged peptides studied here, this implied that loss of the whole tag should be a favored process upon electron capture (Scheme 4). However, as can be seen from Figures 1c and $2 c$, the tag loss peaks were much weaker (by as much as an order of magnitude in the latter case) than the corresponding peaks with loss of the tag and an additional methyl group. Scheme 5 represents two possible pathways to generate the tag loss product with the additional methyl loss, which led to the formation of a charged even-electron species that was detected and a stable radical species with the radical residing on the alpha carbon, which may also exist in several other possible resonance structures. Scheme $\mathbf{5 a}$ is a McLafferty rearrangement, which is both highly likely and a rearrangement with very low activation barrier.

Alternatively, the lost methyl group could come from elsewhere on the peptide such as the valine side chain (Scheme $\mathbf{5 b}$ ). The loss of the TMP tag left the radical site on the $\varepsilon$-carbon of the lysine side chain, which was an unconjugated primary radical, a fairly reactive species prone to further radical rearrangements. This radical may abstract a hydrogen atom from the alpha carbon of the valine residue, leading to the additional loss of a methyl group (Scheme $5 \mathbf{b}$ ). This mechanism was actually supported by the following observations. First, the relative abundance of the tag loss product with additional methyl group loss to that without was much higher for the doubly labeled $\mathrm{A} \beta 25$ than that for the doubly labeled $A \beta 20$. Since the $A \beta 25$ has several leucine and isoleucine residues that could also lead to methyl loss from the tag loss product upon $\mathrm{H}$ atom abstraction from the alpha or beta carbon, this observation lends same support to the model in Scheme $5 \mathbf{b}$, whereas in the case of the $A \beta 20$, for this model to be correct, the $\mathrm{H}$ atom abstraction would have to take place at the alpha carbon of the single valine residue. Second, and more importantly, fragment ions corresponding to additional loss of other alkyl groups such as the ethyl and propyl were observed only in ECD of the $\mathrm{A} \beta 25$, corresponding to the presence of multiple leucine/isoleucine residues. Had Scheme $5 a$ been the major pathway for the combined loss of tag and methyl groups, tag plus ethyl loss would have been observed only if the originally abstracted $\mathrm{H}$ atom was from the beta rather than from the gamma carbon of the lysine side chain.

For singly labeled peptides, the methyl loss peaks were much stronger than the tag loss peaks, particularly for the singly labeled $\mathrm{A} \beta 20$, where it was the most abundant fragment ion (Figure $1 \mathrm{~b}$ ). The methyl group did not appear to come from the TMP tag, since the addition of a second tag greatly reduced the abundance of the methyl loss product for both peptides. Once again, the most likely source of the methyl group was the side chain of the valine residue, where the initially formed radical could abstract a hydrogen atom from the alpha carbon of the valine residue, and the resultant alpha radical could lose one of the two methyl groups to form a stable even-electron species (Scheme 6). Selectively deuterating the TMP tag or the valine residue would help to identify the source of the lost methyl group. For $\mathrm{A} \beta 25$, the alpha radical on one of the isoleucine residues or the beta radical on either the isoleucine or leucine residue could also lead to the loss of a methyl group (Scheme 6), although the methyl loss peak there was much weaker than in the ECD spectrum of the $\mathrm{A} \beta 20$. This might be attributable to the different conformations of the two peptides, with the $\mathrm{A} \beta 20$ 
(a)

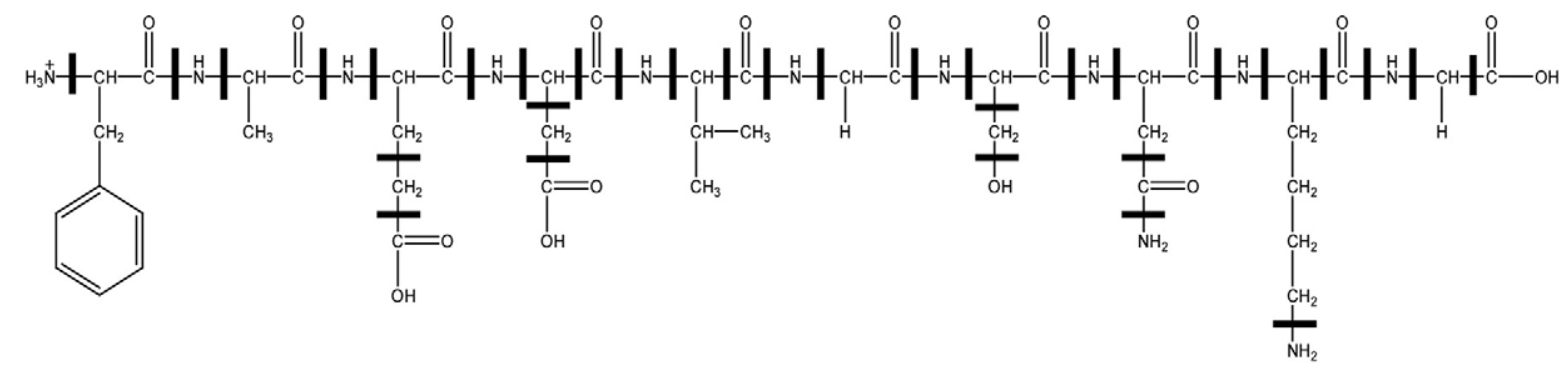

(b)

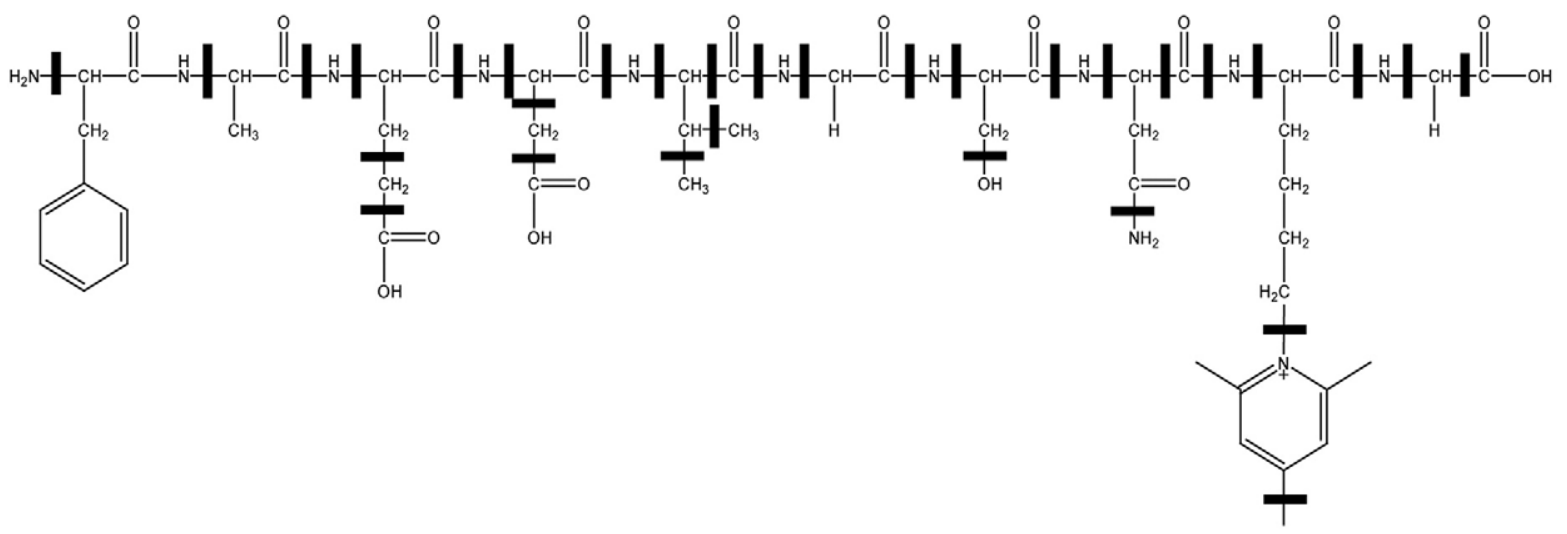

(c)

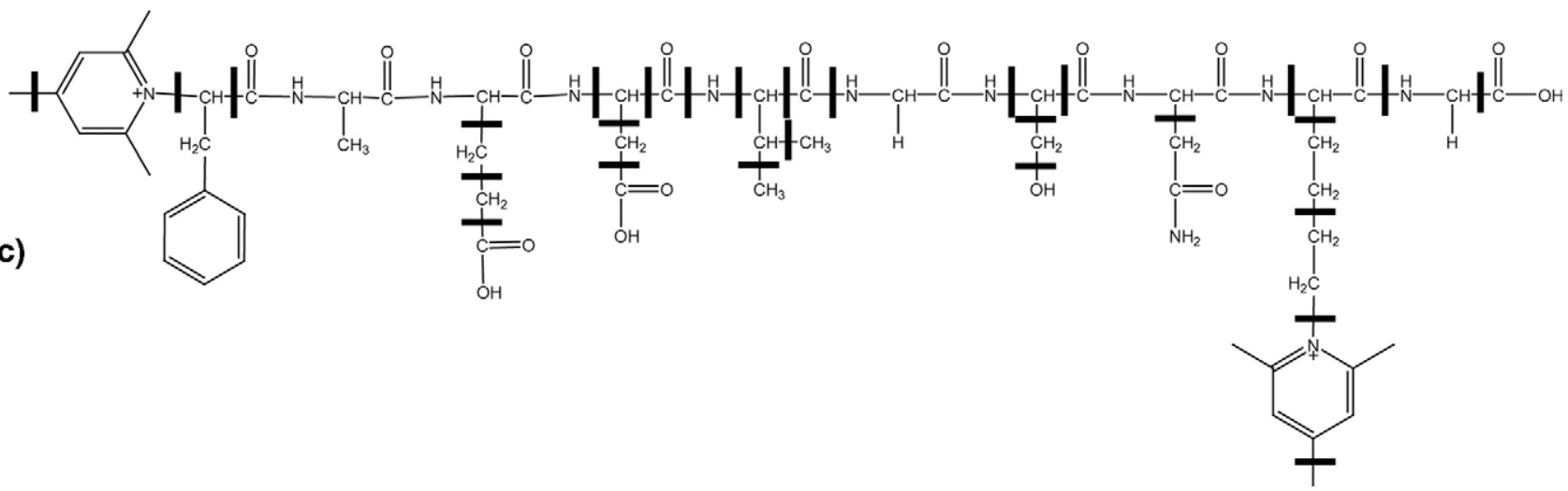

Figure 3. All observed ECD cleavages of the (a) unlabeled, (b) singly labeled, and (c) doubly labeled $\mathrm{A} \beta$ peptide (20-29).

having the valine residue closer to the TMP tag on lysine, and the $\mathrm{A} \beta 25$ having the tag farther away from the isoleucine/leucine residues. Likewise, the dramatic abundance drop of the methyl loss product ions when a second TMP tag was added to the N-terminus may also be a result of the conformational changes.

\section{Other Small Molecule and Side-Chain Losses}

Small molecule and side-chain losses are common in ECD of multiply protonated peptides [21]. The hydrogen atom generated from the neutralized protonated site plays an instrumental role in the proposed mechanism. Such was also the case for the ECD of the unlabeled peptides studied here, where ammonia and water losses as well as side-chain losses from serine, asparagine, lysine, isoleucine, leucine, and methionine residues were observed.
In a previous study, ECD of substance $\mathrm{P}$ modified with coumarin tags produced far more side-chain cleavages than the unmodified peptide, and the abundances of these side-chain cleavage products appeared to increase with the number of the tags [37]. It was believed that the presence of radical traps inhibited the backbone cleavage pathways, thus redirecting the radical to the side chains, possibly by changing the gas-phase conformation of the peptide. A closer examination revealed that the great majority of the side-chain loss products from the ECD of the tagged substance P were also accompanied by tag loss. The (singly) lysine-tagged substance P did produce some "pure" side-chain loss products, albeit in lower abundances. Similar trends were observed here, where most enhanced side-chain cleavages were primarily observed when they were also accompanied by tag loss. One notable difference is the 
(a)

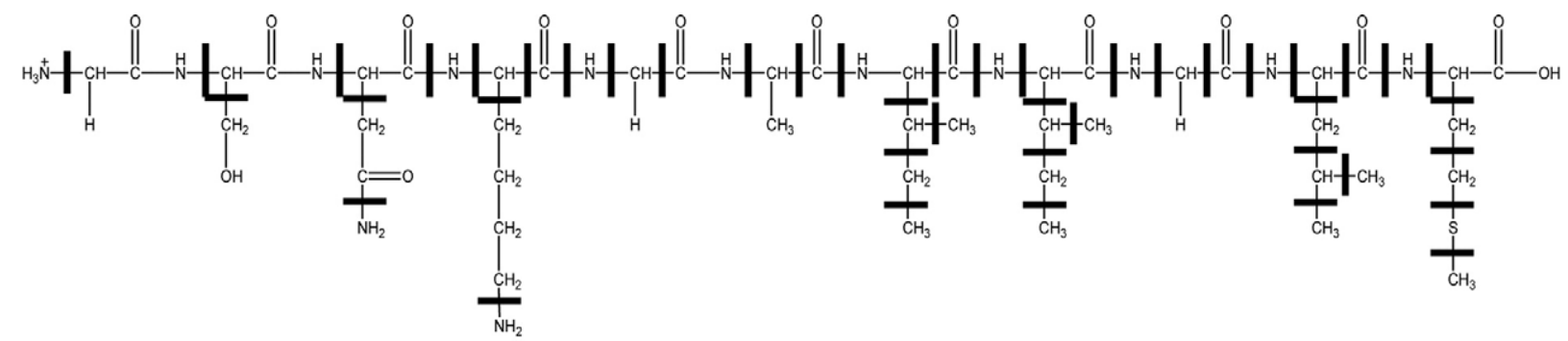

(b)

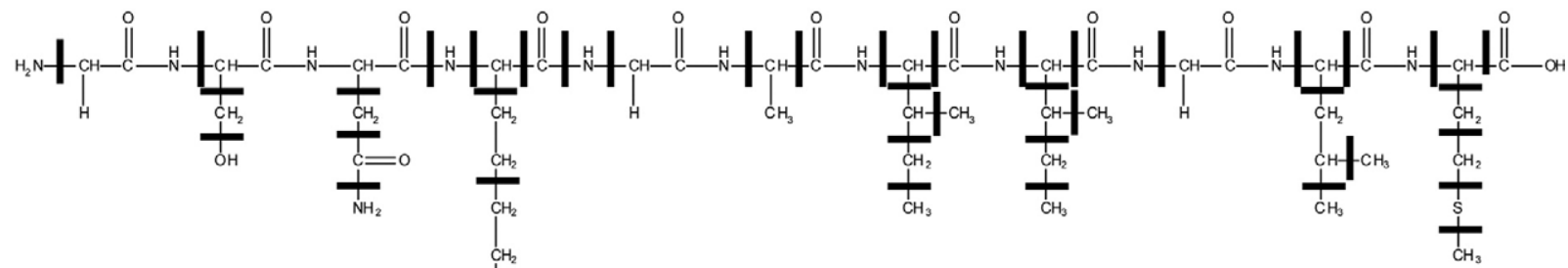

(c)

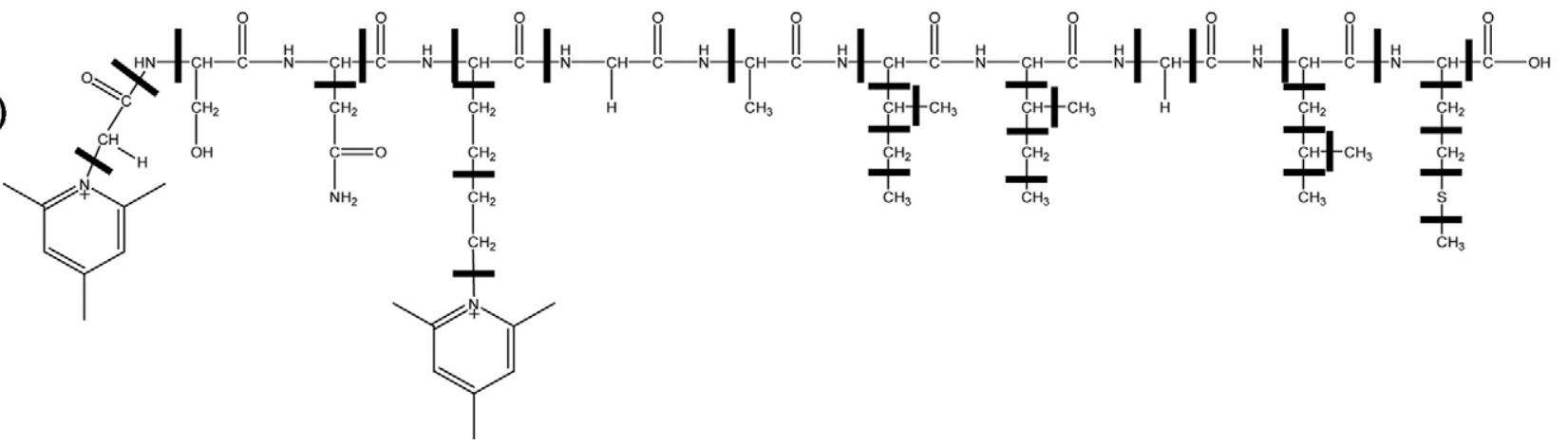

Figure 4. All observed ECD cleavages of the (a) unlabeled, (b) singly labeled, and (c) doubly labeled A $\beta$ peptide (25-35).

abundant solo methyl loss peak observed in singly tagged amyloid peptides and the doubly tagged $\mathrm{A} \beta 20$.

These trends can be explained by the number of available protonation sites and the tag's ability to stabilize a racial. For the singly tagged substance $\mathrm{P}$, the likely charged sites were the arginine side-chain guanidine group and the remaining untagged amino group, which upon electron capture could produce the hydrogen atom initiating side-chain cleavages. For the doubly tagged substance $\mathrm{P}$, one of the charge carriers was the protonated guanidine group and the other most likely was the protonated amide nitrogen on the tagged site. The latter would be the favored neutralization site upon electron capture, which led to the loss of the neutral tag<smiles>CCC(NC)C(C)=O</smiles>

Scheme 4. Tag loss after the electron capture. 
(a)<smiles>C=CC(NC)C(C)=O</smiles>

(b)

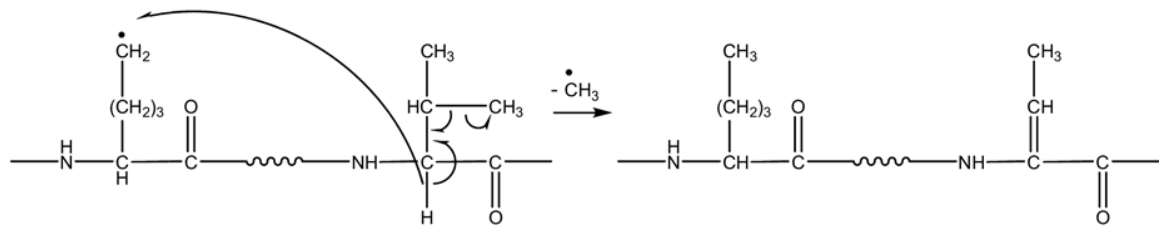

Scheme 5. Methyl group loss from the tag loss product.

and left the radical site on the peptide lysine side chain, capable of inducing secondary side-chain cleavages. As a result, for doubly tagged substance $\mathrm{P}$, all observed side-chain cleavages were from the tag loss products [37].

Unlike the singly tagged substance $\mathrm{P}$, all tagged $\mathrm{A} \beta$ peptides studied here contained at least one nonprotonated charge carrier (the fixed charge tag), which also happened to be the preferred neutralization site because of its larger recombination energy. As discussed earlier, the electron capture at the TMP tag resulted in the loss of the neutral tag as a primary product (although not necessarily the most abundant product), which could undergo secondary side-chain losses because the radical site remaining on the peptide was a primary radical with relatively low stability (Scheme 4). Consequently, in the ECD spectra of the TMP-tagged peptides, whether with one or two tags, most observed side-chain loss products were secondary fragment ions from the tag loss product, just like what was observed in the ECD of the doubly tagged substance P. However, in the ECD spectra of singly labeled $\mathrm{A} \beta$ peptides, some side-chain losses without accompanying tag loss were also observed. These were often accompanied by $\mathrm{NH}_{3}$ loss instead, such as the $-\mathrm{CH}_{3}-\mathrm{NH}_{3}$ peaks in Figures $\mathrm{lb}$ and $2 \mathrm{~b}$, and the $-\mathrm{NH}_{3}-\mathrm{CH}_{2} \mathrm{SCH}_{3}$ peak in Figure $2 \mathrm{~b}$. Thus, the protonated $\mathrm{N}$-terminal amino group may also be a possible neutralization site, even though it may not be the favored one, in accordance with the observation of multiple $\mathrm{z}$ ions in Figure $1 \mathrm{~b}$.

\section{Secondary and Internal Fragment Ions}

Both $\mathrm{d}$ - and $\mathrm{w}$-ion formations resulting from secondary side-chain cleavages after the primary $\mathrm{N}-\mathrm{C}_{\alpha}$ bond cleavage were common in ECD of multiply protonated peptide ions. Their abundances were often dramatically

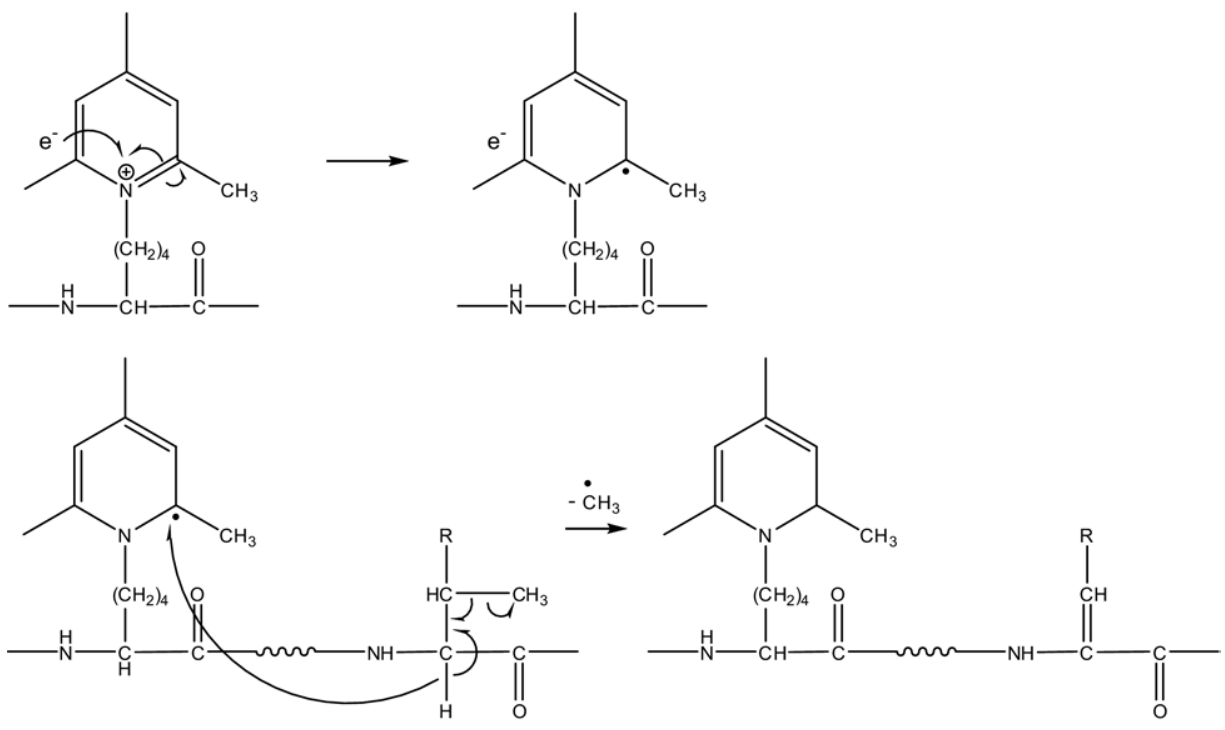

Scheme 6. Methyl loss from the valine $\left(\mathrm{R}=\mathrm{CH}_{3}\right)$ and isoleucine $\left(\mathrm{R}=\mathrm{CH}_{2} \mathrm{CH}_{3}\right)$ side chains. 
increased with increased precursor ion internal energy, such as in hot ECD or AI-ECD, which was very useful in differentiating the isomeric leucine and isoleucine residues $[24,36]$. Other types of secondary fragments requiring radical migration from the alpha carbon at the cleavage site before secondary side-chain cleavages have also been observed previously [13, 25]. For the unlabeled peptides studied here, many $\mathrm{z}$ ions experienced secondary side-chain cleavages (Figures 1a and 2a and Supplementary Tables S-1 and S-4), but none of the c ions displayed any secondary side-chain losses because the latter did not contain a radical site. Some secondary fragment ions resulted from loss of different groups from the same side chain. Thus, the hydrogen atom abstracted did not appear to be limited to those on the backbone alpha carbons; some of the ions observed would require the hydrogen atom on the side chain to be abstracted before secondary cleavages. For example, the $z_{8}$ ion from the ECD of the $A \beta 25$ peptide could lose either the even-electron $\mathrm{CH}_{3}-\mathrm{S}-\mathrm{CH}=\mathrm{CH}_{2}$ molecule or the odd-electron $\mathrm{CH}_{3}-\mathrm{S}-\mathrm{CH}_{2}{ }^{\circ}$ radical (Scheme $\mathbf{7 a}, \mathbf{b}$ ). Complete side-chain loss from the leucine or isoleucine residue was also apparent, which left the radical on the peptide backbone that could initiate further cleavages. This was evident in Figure 2a and Supplementary Table $\mathrm{S}-4$, where $\mathrm{z}_{8}$ ion with multiple side-chain losses was observed.

The ECD spectrum of the singly tagged $A \beta 20$ peptide contained many similar secondary fragment ions as seen in that of the unlabeled peptide. These [ $z-$ $R$ ] ions (where $R$ denotes a side chain) were almost certain to result from the electron capture by the protonated N-terminal amino group because the lysine TMP tag must retain its charge so that they could be detected. Furthermore, several methyl loss peaks from various $\mathrm{z}$ ions were present in the ECD spectrum of the singly labeled $\mathrm{A} \beta 20$ peptide, but were absent in that of the unlabeled peptide. No $\mathrm{z}$ ions smaller than $\mathrm{z}_{6}$ experienced the methyl loss; thus, the methyl group was most likely lost from the valine side chain, instead of from the TMP tag. It was unclear, however, why the presence of a TMP tag enhanced the methyl loss from both the charge-reduced molecular ion and the primary $\mathrm{z}$ ions, given that it did not appear to be directly involved (i.e., the methyl was unlikely to come from the TMP tag). For the singly tagged $\mathrm{A} \beta 25$ peptide, neither $\mathrm{z}$ ions nor secondary fragment ions from $\mathrm{z}$ ions were observed. This was probably a result of the close proximity of the N-terminus and the TMP tag, which made the electron capture at the $\mathrm{N}$-terminus less likely than when they were farther apart, as in the case of the singly tagged $\mathrm{A} \beta 20$ peptide. However, extensive secondary fragmentation was observed on the molecular ion that had lost the neutral tag only or the neutral tag along with partial or complete loss of the lysine side chain (Figure $2 b$ and Supplementary Table S-5), provided that the radical still resided within the peptide after the tag or lysine side-chain loss. ECD of both doubly tagged peptides produced plenty of secondary side-chain loss products after the initial tag or lysine side-chain loss, just like the singly tagged $A \beta 25$ peptide. In the absence of a protonated site, the electron capture was certain to take place at the TMP-tagged site, generating a radical upon neutral tag loss, which can initiate further cleavages.

Finally, some internal fragments were observed with high mass accuracy in both the unlabeled and labeled peptides (Figures 1a and 2a-c, and Supplementary Tables S-1 and S-4-S-6). These have not been previously reported, most likely because of the charge locations (a)

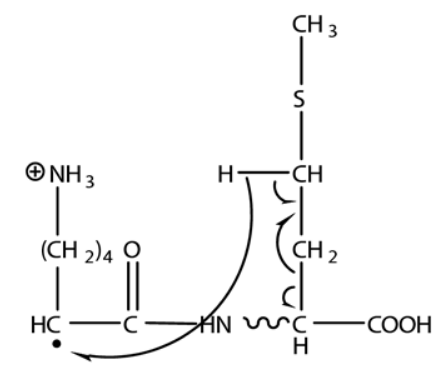

(b)

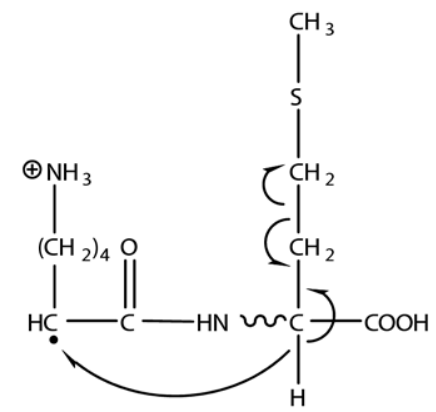

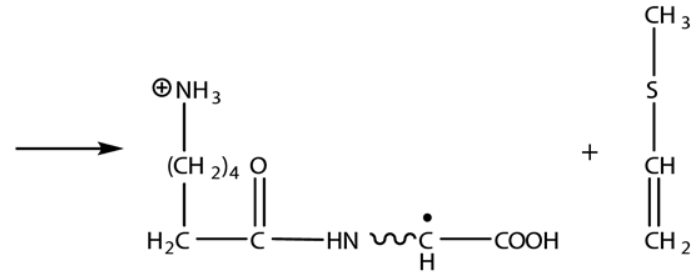

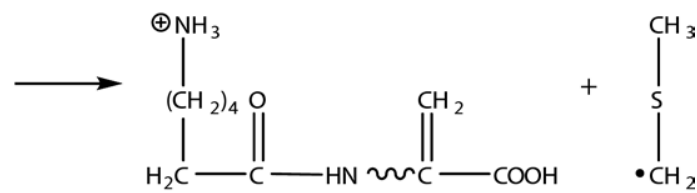

Scheme 7. Methionine side-chain losses from the $z_{8}$ ion. 
near the termini for substance $\mathrm{P}$ and the tryptic peptides commonly studied. The two peptides studied here have one of the charge carriers, the lysine residue, in the middle of the sequence, thus making possible the detection of internal fragment ions generated, particularly when the charge was fixed on the lysine residue. Their abundances were fairly low compared with those of the terminal fragment ions, probably because of the many other channels (such as the secondary side-chain loss channels) present that were more favorable because of low activation energies or less stringent conformational requirements. Nonetheless, the presence of these internal fragments demonstrated further that the freeradical cascade mechanism could play an important role in the backbone cleavages during ECD of linear peptides as well.

\section{Conclusions}

The addition of fixed charge groups (TMP) significantly changed the ECD behavior of two amyloid $\beta$ peptides. In general, a higher number of TMP tags correlated with fewer backbone cleavages and more abundant side-chain cleavages. The TMP tag was chosen because of its ability to stabilize (trap) the originally formed radical upon electron capture, as well as its nonprotonated nature, which was postulated to inhibit the hydrogen atom formation that was essential for the $\mathrm{N}-\mathrm{C}_{\alpha}$ bond cleavage in the dissociation-recapture mechanism. Although low-abundance $\mathrm{H}$ loss products were observed in the ECD spectra of doubly tagged peptides, the $\mathrm{H}$ atoms generated there were not expected to play an important role in backbone cleavages because of the small cross section for its recapture by the peptide and the unlikelihood of the fixed-charge site to form a hydrogen bond with backbone carbonyls to initiate concerted hydrogen atom transfer for $\mathrm{N}-\mathrm{C}_{\alpha}$ bond cleavages during ECD. Still, some c- and z-type ions were observed in the ECD of doubly tagged peptides, demonstrating that there existed other, non- $\mathrm{H}$ atommediated pathways for $\mathrm{c} / \mathrm{z}$-ion formations in ECD, which may be radical driven, or resulted from the coulomb-assisted dissociative electron transfer. However, because the modified peptides often have electronic and conformational properties very different from those of the unmodified ones, these results did not necessarily undermine the importance of the hydrogen atom in the ECD of peptides. In fact, the opposite might be true because the doubly tagged peptides without a protonated site produced far fewer and less abundant backbone cleavages.

The apparent blocking of the backbone fragmentation channels seemed to open up new channels for side-chain cleavages, possibly as a result of the redirection of the radical site toward side chains. Most sidechain cleavages from the TMP-tagged A $\beta$ peptides were accompanied by the tag loss. This reaffirmed that the charge neutralization predominantly occurred at the TMP tag, which could easily lose the tag and generate a primary radical that can initiate further side-chain cleavages. Secondary fragment ions were abundant in the ECD spectra of both $A \beta$ peptides, with or without the TMP tags. Frequently, these ions were the result of secondary cleavages following through-space hydrogen atom abstraction. Future experiments using selectively deuterated TMP tag or amino acid side chains can help to explain different processes in the ECD of these modified peptides. Finally, several internal fragments were observed in the spectra, which provide strong support to the free-radical cascade mechanism.

\section{Acknowledgments}

The authors gratefully acknowledge the financial support from the NIH/NCRR P41RR10888, NIH/NHLBI N01HV28178, NIH/ NIGMS R01GM078293, MSD SCIEX, and ACS Petroleum Research Fund; and thank Dr. Raman Mathur, Dr. Vera B. Ivleva, Dr. Cheng Zhao, Dr. Chunxiang Yao, Dr. Michael Bowman, Konstantine Aizikov, and Nadezda Sargaeva for helpful discussions.

\section{References}

1. Little, D. P.; Speir, J. P.; Senko, M. W.; Oconnor, P. B.; McLafferty, F. W. Infrared Multiphoton Dissociation of Large Multiply-Charged Ions for Biomolecule Sequencing. Anal. Chem. 1994, 66, 2809-2815.

2. Gauthier, J. W.; Trautman, T. R.; Jacobson, D. B. Sustained OffResonance Irradiation for Collision-Activated Dissociation Involving Fourier-Transform Mass-Spectrometry-Collision-Activated Dissociation Technique That Emulates Infrared Multiphoton Dissociation. Anal. Chim. Acta 1991, 246, 211-225.

3. Zubarev, R. A.; Kelleher, N. L.; McLafferty, F. W. Electron Capture Dissociation of Multiply Charged Protein Cations. A Nonergodic Process. J. Am. Chem. Soc. 1998, 120, 3265-3266.

4. Kelleher, R. L.; Zubarev, R. A.; Bush, K.; Furie, B.; Furie, B. C.; McLafferty, F. W.; Walsh, C. T. Localization of Labile Posttranslational Modifications by Electron Capture Dissociation: The Case of gammaCarboxyglutamic Acid. Anal. Chem. 1999, 71, 4250-4253.

5. Stensballe, A.; Jensen, O. N.; Olsen, J. V.; Haselmann, K. F.; Zubarev, R. A. Electron Capture Dissociation of Singly and Multiply Phosphorylated Peptides. Rapid Commun. Mass Spectrom. 2000, 14, 1793-1800.

6. Shi, S. D.-H.; Hemling, M. E.; Carr, S. A.; Horn, D. M.; Lindh, I.; McLafferty, F. W. Phosphopeptide/Phosphoprotein Mapping by Electron Capture Dissociation Mass Spectrometry. Anal. Chem. 2001, 73, 19-22.

7. Cooper, H. J.; Hakansson, K.; Marshall, A. G. The Role of Electron Capture Dissociation in Biomolecular Analysis. Mass Spectrom. Rev. 2005, 24, 201-222.

8. Liu, H.; Hakansson, K. Electron Capture Dissociation of Tyrosine O-Sulfated Peptides Complexed with Divalent Metal Cations. Anal. Chem. 2006, 78, 7570-7576.

9. Horn, D. M.; Ge, Y.; McLafferty, F. W. Activated Ion Electron Capture Dissociation for Mass Spectral Sequencing of Larger (42 kDa) Proteins. Anal. Chem. 2000, 72, 4778-4784.

10. Breuker, K.; Oh, H. B.; Horn, D. M.; Cerda, B. A.; McLafferty, F. W. Detailed Unfolding and Folding of Gaseous Ubiquitin Ions Characterized by Electron Capture Dissociation. J. Am. Chem. Soc. 2002, 124, 6407-6420.

11. Lin, C.; O'Connor, P. B.; Cournoyer, J. J. Use of a Double Resonance Electron Capture Dissociation Experiment to Probe Fragment Intermediate Lifetimes. J. Am. Soc. Mass Spectrom. 2006, 17, 1605-1615.

12. Xie, Y.; Zhang, J.; Yin, S.; Loo, J. A. Top-Down ESI-ECD-FT-ICR Mass Spectrometry Localizes Noncovalent Protein-Ligand Binding Sites. I. Am. Chem. Soc. 2006, 128, 14432-14433.

13. Lin, C.; Cournoyer, J. C.; O'Connor, P. B. Probing the Gas Phase Folding Kinetics of Peptide Ions by IR Activated DR-ECD. J. Am. Soc. Mass Spectrom. 2008, 19, 780-789.

14. Zubarev, R. A.; Horn, D. M.; Fridriksson, E. K.; Kelleher, N. L.; Kruger, N. A.; Lewis, M. A.; Carpenter, B. K.; McLafferty, F. W. Electron Capture Dissociation for Structural Characterization of Multiply Charged Protein Cations. Anal. Chem. 2000, 72, 563-573.

15. Zubarev, R. A. Reactions of Polypeptide Ions with Electrons in the Gas Phase. Mass Spectrom. Rev. 2003, 22, 57-77.

16. Bakhtiar, R.; Guan, Z. Q. Electron Capture Dissociation Mass Spectrometry in Characterization of Peptides and Proteins. Biotechnol. Lett. 2006, $28,1047-1059$.

17. Zubarev, R. A.; Haselmann, K. F.; Budnik, B.; Kjeldsen, F.; Jensen, F. Towards an Understanding of the Mechanism of Electron-Capture 
Dissociation: A Historical Perspective and Modern Ideas. Eur. J. Mass Spectrom. 2002, 8, 337-349.

18. Meng, F. Y.; Forbes, A. I.; Miller, L. M.; Kelleher, N. L. Detection and Localization of Protein Modifications by High Resolution Tandem Mass Spectrometry. Mass Spectrom. Rev. 2005, 24, 126-134.

19. Syrstad, E. A.; Turecek, F. Toward a General Mechanism of Electron Capture Dissociation. I. Am. Soc. Mass Spectrom. 2005, 16, 208-224.

20. Breuker, K.; Oh, H. B.; Cerda, B. A.; Horn, D. M.; McLafferty, F. W. Hydrogen Atom Loss in Electron-Capture Dissociation: A Fourier Transform-Ion Cyclotron Resonance Study with Single Isotopomeric Ubiquitin Ions. Eur. J. Mass Spectrom. 2002, 8, 177-180.

21. Cooper, H. J.; Hudgins, R. R.; Hakansson, K.; Marshall, A. G. Characterization of Amino Acid Side Chain Losses in Electron Capture Dissociation. J. Am. Soc. Mass Spectrom. 2002, 13, 241-249.

22. Cooper, H. J.; Hakansson, K.; Marshall, A. G.; Hudgins, R. R.; Haselmann, K. F.; Kjeldsen, F.; Budnik, B. A.; Polfer, N. C.; Zubarev, R. A. Letter: The Diagnostic Value of Amino Acid Side-Chain Losses in Electron Capture Dissociation of Polypeptides. Comment on: "Can the (M-Center Dot-X) Region in Electron Capture Dissociation Provide Reliable Information on Amino Acid Composition of Polypeptides?" [Eur. J. Mass Spectrom. 2002, 8, 461-469]. Eur. J. Mass Spectrom. 2003, 9, 221-222.

23. Savitski, M. M.; Nielsen, M. L.; Zubarev, R. A. Side-Chain Losses in Electron Capture Dissociation to Improve Peptide Identification. Anal. Chem. 2007, 79, 2296-2302.

24. Kjeldsen, F.; Haselmann, K. F.; Budnik, B. A.; Jensen, F.; Zubarev, R. A. Dissociative Capture of Hot (3-13 eV) Electrons by Polypeptide Polycations: An Efficient Process Accompanied by Secondary Fragmentation. Chem. Phys. Lett. 2002, 356, 201-206.

25. Cooper, H. J.; Hudgins, R. R.; Hakansson, K.; Marshall, A. G. Secondary Fragmentation of Linear Peptides in Electron Capture Dissociation. Int. J. Mass Spectrom. 2003, 228, 723-728.

26. Leymarie, N.; Costello, C. E.; O'Connor, P. B. Electron Capture Dissociation Initiates a Free Radical Reaction Cascade. J. Am. Chem. Soc. 2003, 125, 8949-8958.

27. Demirev, P. A. Generation of Hydrogen Radicals for Reactivity Studies in Fourier Transform Ion Cyclotron Resonance Mass Spectrometry. Rapid Commun. Mass Spectrom. 2000, 14, 777-781.

28. Turecek, F. N-C-alpha Bond Dissociation Energies and Kinetics in Amide and Peptide Radicals. Is the Dissociation a Non-Ergodic Process? J. Am. Chem. Soc. 2003, 125, 5954-5963.

29. Hudgins, R. R.; Hakansson, K.; Quinn, J. P.; Hendrickson, C. L.; Marshall, A. G. Electron Capture Dissociation of Peptides and Proteins Does Not Require a Hydrogen Atom Mechanism. Proceedings of the 50th ASMS Conference on Mass Spectrometry and Allied Topics, Orlando, FL, 2000.

30. Sobczyk, M.; Anusiewicz, W.; Berdys-Kochanska, J.; Sawicka, A.; Skurski, P.; Simons, J. Coulomb-Assisted Dissociative Electron Attachment: Application to a Model Peptide. J. Phys. Chem. A 2005, 109, 250-258.

31. Chamot-Rooke, J.; Malosse, C.; Frison, G.; Turecek, F. Electron Capture in Charge-Tagged Peptides. Evidence for the Role of Excited Electronic States. J. Am. Soc. Mass Spectrom. 2007, 18, 2146-2161.

32. O'Connor, P. B.; Lin, C.; Cournoyer, J. J.; Pittman, J. L.; Belyayev, M.; Budnik, B. A. Long-Lived Electron Capture Dissociation Product Ions Experience Radical Migration via Hydrogen Abstraction. J. Am. Soc. Mass Spectrom. 2006, 17, 576-585.

33. Savitski, M. M.; Kjeldsen, F.; Nielsen, M. L.; Zubarev, R. A. Hydrogen rearrangement to and from radical $\mathrm{z}$ fragments in electron capture dissociation of peptides. J. Am. Soc. Mass Spectrom. 2007, 18, 113-120.

34. Tsybin, O. Y.; He, H.; Emmett, M. R.; Hendrickson, C. L.; Marshall, A. G. Ion Activation in Electron Capture Dissociation Can Distinguish Between N-terminal and C-terminal Product Ions. Anal. Chem. 2007, 79, $7596-7602$.

35. Kjeldsen, F.; Zubarev, R. Secondary Losses via gamma-Lactam Formation in Hot Electron Capture Dissociation: A Missing Link to Complete De Novo Sequencing of proteins? J. Am. Chem. Soc. 2003, 125, 66286629.

36. Tsybin, Y. O.; Witt, M.; Baykut, G.; Kjeldsen, F.; Hakansson, P. Combined Infrared Multiphoton Dissociation and Electron Capture Dissociation with a Hollow Electron Beam in Fourier Transform Ion Cyclotron Resonance Mass Spectrometry. Rapid Commun. Mass Spectrom. 2003, 17, 1759-1768.

37. Belyayev, M. A.; Cournoyer, J. J.; Lin, C.; O'Connor, P. B. The Effect of Radical Trap Moieties on Electron Capture Dissociation Spectra of Substance P. J. Am. Soc. Mass Spectrom. 2006, 17, 1428-1436.

38. Jones, J. W.; Sasaki, T.; Goodlett, D. R.; Turecek, F. Electron Capture in Spin-Trap Capped Peptides. An Experimental Example of Ergodic Dissociation in Peptide Cation-Radicals. J. Am. Soc. Mass Spectrom. 2007, 18, 432-444.
39. Roth, K. D. W.; Huang, Z. H.; Sadagopan, N.; Watson, J. T. Charge Derivatization of Peptides for Analysis by Mass Spectrometry. Mass Spectrom. Rev. 1998, 17, 255-274.

40. Wagner, D. S.; Salari, A.; Gage, D. A.; Leykam, J.; Fetter, J.; Hollingsworth, R.; Watson, J. T. Derivatization of Peptides to Enhance Ionization Efficiency and Control Fragmentation during Analysis by FastAtom-Bombardment Tandem Mass-Spectrometry. Biol. Mass Spectrom. 1991, 20, 419-425.

41. Zaia, J.; Biemann, K. Comparison of Charged Derivatives for HighEnergy Collision-Induced Dissociation Tandem Mass-Spectrometry. J. Am. Soc. Mass Spectrom. 1995, 6, 428-436.

42. Vath, J. E.; Biemann, K. Microderivatization of Peptides by Placing a Fixed Positive Charge at the N-Terminus to Modify High-Energy Collision Fragmentation. Int. J. Mass Spectrom. Ion Process. 1990, 100, 287-299.

43. Adamczyk, M.; Gebler, J. C.; Wu, J. Charge Derivatization of Peptides to Simplify Their Sequencing with an Ion Trap Mass Spectrometer. Rapid Commun. Mass Spectrom. 1999, 13, 1413-1422.

44. Chagit, D.; Rabkin, E.; Tsoglin, A. A New Charge Derivatization Procedure for Peptide Sequencing. Org. Biomol. Chem. 2005, 3, 2503 2504.

45. Syka, J. E. P.; Coon, J. J.; Schroeder, M. J.; Shabanowitz, J.; Hunt, D. F. Peptide and Protein Sequence Analysis by Electron Transfer Dissociation Mass Spectrometry. Proc. Natl. Acad. Sci. U. S. A. 2004, 101, 9528-9533.

46. Chamot-Rooke, J.; van der Rest, G.; Dalleu, A.; Bay, S.; Lemoine, J. The Combination of Electron Capture Dissociation and Fixed Charge Derivatization Increases Sequence Coverage for O-Glycosylated and OPhosphorylated Peptides. J. Am. Soc. Mass Spectrom. 2007, 18, 1405-1413.

47. Xia, Y.; Gunawardena, H. P.; Erickson, D. E.; McLuckey, S. A. Effects of Cation Charge-Site Identity and Position on Electron-Transfer Dissociation of Polypeptide Cations. I. Am. Chem. Soc. 2007, 129, 12232-12243.

48. Gunawardena, H. P.; Gorenstein, L.; Erickson, D. E.; Xia, Y.; McLuckey, S. A. Electron Transfer Dissociation of Multiply Protonated and Fixed Charge Disulfide Linked Polypeptides. Int. J. Mass Spectrom. 2007, 265, $130-138$.

49. O'Connor, P. B.; Pittman, J. L.; Thomson, B. A.; Budnik, B. A.; Cournoyer, J. C.; Jebanathirajah, J.; Lin, C.; Moyer, S.; Zhao, C. A New Hybrid Electrospray Fourier Transform Mass Spectrometer: Design and Performance Characteristics. Rapid Commun. Mass Spectrom. 2006, 20, 259-266.

50. Jebanathirajah, J. A.; Pittman, J. L.; Thomson, B. A.; Budnik, B. A.; Kaur P.; Rape, M.; Kirschner, M.; Costello, C. E.; O'Connor, P. B. Characterization of a New qQq-FTICR Mass Spectrometer for Post-Translational Modification Analysis and Top-Down Tandem Mass Spectrometry of Whole Proteins. J. Am. Soc. Mass Spectrom. 2005, 16, 1985-1999.

51. Johnson, R. S. Determination of Peptide and Protein Structure by Tandem Mass Spectrometry (Ph.D. Dissertation). Massachusetts Institute of Technology: Cambridge, MA, 1988.

52. Johnson, R. S.; Martin, S. A.; Biemann, K. Collision-Induced Fragmentation of $(\mathrm{M}+\mathrm{H})^{+}$Ions of Peptides. Side-Chain Specific Sequence Ions. Int. J. Mass Spectrom. Ion Process. 1988, 86, 137-154.

53. King, L. C.; Ozog, F. J. Reactions of Pyrylium and Pyridinium Salts with Amines. J. Org. Chem. 1955, 20, 448-454.

54. Zubarev, R. A.; Kruger, N. A.; Fridriksson, E. K.; Lewis, M. A.; Horn, D. M.; Carpenter, B. K.; McLafferty, F. W. Electron Capture Dissociation of Gaseous Multiply-Charged Proteins Is Favored at Disulfide Bonds and Other Sites of High Hydrogen Atom Affinity. J. Am. Chem. Soc. 1999, 121, 2857-2862.

55. Cooper, H. J. Investigation of the Presence of b Ions in Electron Capture Dissociation Mass Spectra. J. Am. Soc. Mass Spectrom. 2005, 16, 1932 1940.

56. Nguyen, V. Q.; Turecek, F. Gas-Phase Protonation of Pyridine. A Variable-Time Neutralization-Reionization and Ab Initio Study of Pyridinium Radicals. J. Mass Spectrom. 1997, 32, 55-63.

57. Turecek, F. Syrstad, E. A. Mechanism and Energetics of Intramolecular Hydrogen Transfer in Amide and Peptide Radicals and CationRadicals. J. Am. Chem. Soc. 2003, 125, 3353-3369.

58. Hodyss, R.; Cox, H. A.; Beauchamp, J. L. Bioconjugates for Tunable Peptide Fragmentation: Free Radical Initiated Peptide Sequencing (FRIPS). J. Am. Chem. Soc. 2005, 127, 12436-12437.

59. Ly, T.; Julian, R. R. Residue-Specific Radical-Directed Dissociation of Whole Proteins in the Gas Phase. J. Am. Chem. Soc. 2008, 130, 351-358.

60. Ly, T.; Julian, R. R. Fast Formation of Sidechain Aryl Radicals by UV Irradiation Produces Selective Fragmentation of Whole Proteins. 2008 Conference on Ion Chemistry and Mass Spectrometry, Lake Arrowhead, CA, 2008 . 